\title{
Preliminary Notes on the Reproduction of Teleostean Fishes in the South-Western District.
}

\author{
By
}

Ernest W. L. Holt.

DURING the present year tow-netting has been carried on with such continuity as the weather permitted, and the fish-ova and larvæ thereby obtained have been studied by Mr. S. D. Scott during the winter months, and by myself since the spring. While reserving a general account of the results until the close of the season, it seems advisable to deal now, in however preliminary a manner, with a few species, an addition to the existing knowledge of which may be found of immediate use by workers in the same field. I take this opportunity of expressing my indebtedness to $\mathrm{Mr}$. Scott for observing certain eggs which I was obliged to leave at the Laboratory at a stage too little advanced for specific determination.

\section{Capros aper.-Linn.}

The ova of this fish were artificially fertilized by Cunningham (Journ. M.B.A., N. S., I., 1889, p. 10) on August 15th, 1897, and lived until a stage immediately prior to the outgrowth of a free tail, the embryo exhibiting black chromatophores at the sides, near the dorsal median line. The dimensions of the ovum at the latest stage studied are stated to be 1.2 by $1.5 \mathrm{~mm}$., that of the oil-globule $19 \mathrm{~mm}$.

One pelagic egg with a single oil-globule is very like another until the embryo is so far advanced as to exhibit specifically diagnostic characters, and I was unable to identify tow-net eggs from the above description. However, on the 25th June, 1897, I was able to fertilize ova taken from ripe parents trawled on the Eddystone ground; and some of these hatched out in due course, and, indeed, survived until of the yolk there remained nothing but the oil-globule. I am therefore able to give a sufficiently exact description of the development in ovo and early larval stages. 
Artificially fertilized eggs measured from .915 to $.955 \mathrm{~mm}$; the single oil-globule $\cdot 15$ to $\cdot 16 \mathrm{~mm}$. The oil-globule was colourless, but dark and smoky.

Tow-net eggs, which can be identified with this species.without any risk of error, measure from 97 to 99 , the oil-globule from $\cdot 15$ to $165 \mathrm{~mm}$.; and it may be noted that the oil-globule is usually, but not invariably, of a bright yellow colour-a matter of no real specific importance. Including all tow-net eggs, which seem to me to belong to this species, the diameter varies from .93 to $1.01 \mathrm{~mm}$.

The zona presents no features of interest, the surface corrugations observable in the newly-extruded ova disappearing as development proceeds.

Black pigment, as stated by Cunningham, appears before the outgrowth of a free tail. At the stage when that organ manifests itself as a short prominence I find that faint black chromatophores are present along the head and trunk, but chiefly on either side of the middle line. At the posterior end they extend on to the yolk sac, forming a small marginal group outlining the end of the trunk. The oil-globule at this stage is postero-ventral.

Before the tail has attained any considerable length yellow chromatophores appear along the sides of the embryo, and a few of each colour associate themselves with the oil-globule, which has (usually) become posterior in position. The chromatophores are very frequently on the hinder face of the globule. The skin shows a tendency to become papillate.

By the time the tail is of equal length with the trunk large black and yellow chromatophores extend along the sides of the latter, upon the rectal region, and rather irregularly along the tail, showing a tendency to form a posterior pigment bar. In all specimens which $I$ have seen the epidermis is by this time more or less distinctly papillate, especially on the yolk sac. The papillæ are ovoidal, and not connected with each other by apparent ridges or striæ. Usually they are extremely conspicuous, and as characteristic of the species as such variable structures ever are in Teleostean embryos.

The newly-hatched larva measures, in one instance, $2.09 \mathrm{~mm}$. The hind end of the yolk is $1.38 \mathrm{~mm}$. from the snout, and $\cdot 25$ in front of the anus, which is thus considerably posterior to median. The wide interspace between yolk and anus is characteristic of all larvæ which I have seen, but there are minor differences of dimension. Thus another specimen, soon after hatching, is $2.85 \mathrm{~mm}$. long, and there is a space of $\cdot 44 \mathrm{~mm}$. between yolk and anus. In some cases the yolk is ovoidal, and extends in front of the snout, but usually it appears to be more oblong in profile. The oil-globule is normally posterior, but may be 
ventral, in which case it is unaccompanied by pigment; and it may be remarked that minor differences in the position of oil globules do not deserve the attention that has sometimes been bestowed on them.

Pigment is rather variable, but is never present on the marginal fins nor about the yolk, except along its posterior edge and about the globule. Chromatophores of both colours (the yellow being goldenbrown by transmitted light) are scattered along the head, trunk, and tail of the larva. These are of large size, stellate or dendritic, and arranged for the most part along the dorsal and ventral regions. There may be an approach towards a postanal bar by discontinuity posterior to the rectal region, but this is never well marked. Chromatophores extend some way along the hind wall of the rectum, and, as we have seen, along the hinder profile of the yolk. The skin is markedly papillate, but the margins of the fins are devoid of the digitiform cells noticeable in Arnoglossus or Coris. The notochord is multicolumnar.

In later stages the larva becomes characterised by the development of a very strongly marked renal band of very large black chromatophores, extending from the otocyst to about the anterior third of the tail. A dorsal band, corresponding posteriorly to the first, extends forward about half-way along the abdominal region. A third ventral abdominal band occupies the greater part of the abdominal length, and the chromatophores on the dorsum may form a fourth, extending from the cerebellar region to a little behind the shoulder girdle. Yellow pigment seems to be everywhere associated with the black, but is almost completely masked where the latter exists. It is conspicuous, however, on the sides, especially post-anally, and on the snout, mid-brain, and otocystic region. More or fewer black chromatophores are present about the head in the regions named, and also on the lower jaw and isthmus. The fins are absolutely devoid of pigment, except where a little extends post-anally from each margin of the tail. There is no pigment at all about the posterior two-thirds of the tail of the larva.

At this stage, the most advanced reached by my artificially fertilized ova, as also by tow-net specimens, the larva measures $2.98 \mathrm{~mm}$., of which 1.55 is anterior to the anus, and 1.97 is pigmented. The yolk is only represented by the remains of the oil-globule. The liver and gut are well developed, the latter still without convolution. The mid-brain is elevated, and there is a distinct approach to the rostral prominence of the adult. The trunk is only of moderate depth, but the posterior half of the tail tapers rather suddenly. The marginal fins are only of moderate width, the dorsal having its origin behind the mid-brain. The epidermis remains markedly papillate, but the outline of the fin-ridge is unbroken, save at the caudal extremity, where it is somewhat pectinate, 
embryonic rays occurring basally in this part. The pectoral fin is of the usual fan-like type, and of the ordinary dimensions. The otocyst is smaller than the eye, which is pigmented and obviously functional. The gape is of moderate extent, the lower jaw, as usual, slightly projecting.

Older stages of this larva seem to me to be represented by a number of examples taken in the bottom tow-net about two miles off Fowey river, on the 29th and 30th June. I did not measure, nor very closely examine, any of these in the fresh condition. None were alive when the nets came on deck, so that the present dimensions of the smallest are no doubt less than the original, since young fish-larvæ always shrink unless they are actually killed in a suitable fixing medium. At present the dimensions, roughly measured, are from 5 to $6.5 \mathrm{~mm}$.

The smallest specimens agree with the oldest of those which I reared from the egg in the distribution and arrangement of the black pigment, and in the general conformation, allowing for the difference in age. Thus the trunk is somewhat deeper, and the flexure of the caudal extremity (by hypural development) more accentuated. The rostral prominence is no longer conspicuous.* Yellow pigment, if present, was not a prominent feature, and its disappearance is in accordance with the known developmental phases of other species.

From this stage the series passes without a break to the largest example, which measures $6.6 \mathrm{~mm}$. in total length, of which $.90 \mathrm{~mm}$. is occupied by the caudal fin, and about 1.50 by the head. The greatest height of the body, without vertical fins, is $1.25 \mathrm{~mm}$. In general conformation the larva bears some resemblance to a Labrus, save that the anterior profile is more rounded. The mouth is large, the snout shorter than the eye, which measures 54 in horizontal diameter. The body is laterally compressed, but the dorsal and ventral profiles are still nearly parallel, and not arched, as in the adult: posteriorly the tail tapers rather rapidly, but the caudal peduncle is, nevertheless, of considerable vertical width. The caudal fin is almost completely "homocercal." The dorsal and anal fins are represented by embryonic rays.

Of yellow pigment I saw none in the fresh condition, but black chromatophores are abundant, and very strikingly distributed. A sheet of stellate chromatophores, irregularly arranged in about ten longitudinal rows, clothes the side of the fish from the shoulder girdle to the hind end of the (permanent) anal fin. Dorsally the sheet does not extend quite so far, as its hind margin is oblique. Its dorsal

* In Callionymus an approach to the rostral prominence of the adult has been noted in the early larva, but is shown to become masked in subsequent stages, to reappear with the final assumption of the adult characters (Cf. Trans. R. Dub. Soc., v., ii., pl. iii.). 
outline does not quite reach the middle of the back, and, post-anally, it is not quite continuous with a row of chromatophores which appears at the base of the anal fin. In front the outline is also oblique, the anterior edge passing from the top of the shoulder girdle to a point on the abdominal margin somewhat posterior to the ventral end of the clavicle, and, on the abdomen generally and its dorsal parts in particular, the chromatophores are less closely set than elsewhere. There are some large chromatophores on the top and otocystic regions of the head. Beyond these there are only a few quite insignificant chromatophores at the base of the dorsal and on the caudal peduncle; but the eyes are, of course, fully pigmented. The larva thus appears, to the naked eye, to be clothed in a continuous sheet of grey, except on the head and caudal peduncle. I do not know at what period the red colour of the adult is assumed, but have seen Mediterranean specimens of about $1 \frac{1}{2}$ inches, which were dull grey in colour.

Day (Brit. Fish., i. p. 137), writing of the colours, regards the fish as "remarkable, in that it may be banded or plain, the bands, it having been suggested, being due to the example having been in a dark locality." In all examples which I have seen a number of bands could be detected by careful observation, viz., curved bands about the dorsal parts, which are never at all conspicuous, and a series of vertical bands. I found, on examination, that the vertical bands were the most conspicuous in those examples in which the general red colour was of a bright scarlet, and that these fish were males in breeding condition. The females, also in full sexual production, were much duller in general colouration, with only very faint vertical bands. Day, previous to the conclusion noted above, quotes Dunn to the effect that the bands fade after spawning, but no one seems to have remarked their apparent sexual significance. I do not know if this colour dimorphism is accompanied by any structural difference, but mean to examine the matter.

\section{Phrynorhombus unimaculatus.-Risso.}

Our knowledge of the reproduction of this fish rests upon the single record, by the late George Brook (4th Rep. S.F.B.), of the capture of a ripe female. The ovarian eggs, which were observed to contain a single oil-globule, measured $96 \mathrm{~mm}$. after preservation.

On the 1st June of the present year three examples were trawled in Teignmouth Bay by Mr. S. D. Scott and myself, and proved to consist of a male and two females in breeding condition. An attempt to artificially fertilize the ova from one of these was only partially successful, since the male, which was dead, was not quite ripe, and only a little milt could be obtained by cutting up the testes. 
However, a certain number of ova were impregnated, but while several survived up to a late stage of development, only one hatched.

The unfertilized ova immediately after extrusion were found to measure from .92 to $.93 \mathrm{~mm}$. in diameter. After fertilization, ova measured during the progress of development varied from .90 to .99 $\mathrm{mm}$. The single oil-globule measured from 16 to $\cdot 18 \mathrm{~mm}$. In the early condition the globule exhibited a distinct yellow or greenish yellow colour, a trace of which remained almost up to the time of hatching.

Sixty-six hours after fertilization the embryo had a free tail equal in length to the head and trunk. Pigment was present in the form of small black chromatophores rather profusely distributed over the embryo, except at the extremity of the tail, and more sparsely over the yolk. Pale yellow pigment was present on the embryo, imparting a uniform yellow tinge, the individual chromatophores not being visible under a moderately high power. The epidermis was beset with a not very conspicuous reticulation of minute papillæ.

Ninety hours after fertilization a single larva had hatched; it measured $2.38 \mathrm{~mm}$. in total length, the marginal anus $1.07 \mathrm{~mm}$. from the snout, being slightly anterior to median. The rectum was distinctly separate from the yolk. Yellow pigment was present on all parts of the larva (except the end of the tail), but in greatest abundance, in so far as concerns those parts, along the dorsal and ventral regions of the head, trunk, and tail. On the marginal fins and yolk-sac it was present in scattered dendritic chromatophores, rather more abundantly on the fins of the posterior half of the tail than anteriorly. Small black chromatophores occurred sparsely over the entire general surface, more diffusely on the posterior part of the tail (not fins) than at any other point, but on the dorsal fin were confined to the immediate neighbourhood of the margin. A small pectoral fin was observable, and opposite to this was a slight inflection of the margin of the dorsal fin, which latter commenced to rise, as is usual in newly-hatched larvæ, near the level of the hind end of the otocyst. The oil-globule was posterior in position. The epidermis was beset with minute papillæ or tubercles, with some indication of connecting ridges or striæ.

The larva did not survive to exhibit any more advanced stage of development, and none of the remaining eggs hatched.

I am in some doubt as to whether this observation of the early stages of $P$. unimaculatus throws any light on previously known but undetermined ova and larvæ. The form that at once suggests itself in this connection is the Species F of McIntosh and Prince, which has also been described by myself (Trans. $R$. Dub. Soc., s. ii., v. pt. ii. p. 101), and has more recently been recognised by Ehrenbaum at Heligoland (Eier $u$. 
Larv. v. Fisch. d. deustch. Bucht, i., 1897, p. 317). The dimensions are no obstacle to the identity of the two forms, since, if Species $\mathrm{F}$ is truly a single species, its diameter ranges from $\cdot 75$ to $\cdot 9906 \mathrm{~mm}$. The extremes are rather far apart, though I am not prepared to say that the variation is too great, since one is constantly encountering fresh evidence of the elasticity of the dimensions of Teleostean ova. In comparing the larval $P$. unimaculatus with my own notes and drawings of Species $\mathrm{F}, \mathrm{I}$ find no discrepancies of pigment and general conformation that are in themselves of specific importance.

In discussing the affinities of the egg and larva, McIntosh* and Ehrenbaum have laid stress on the absence of $P$. unimaculatus from the fauna of their respective districts. With all respect, I would submit that such absence may well be more apparent than real, recalling the use which Cunningham has shown the Topknots to make of their marginal fins. A fish which habitually clings to the vertical faces of rocks is well fitted to elude the ordinary collecting apparatus, and is taken, if at all, largely by chance.

I do not say that $P$. unimaculatus is present in the neighbourhood of Heligoland or St. Andrews, but I think that it might be, without attracting human attention.

The real objection to the identity of Species $\mathrm{F}$ with the Topknot now under discussion seems to me to lie in the epidermal structure. My solitary larva certainly did not exhibit the reticulo-papillate arrangement of epidermal cells in a degree nearly as well marked as in the few specimens of $\mathrm{F}$ which have come under my notice; and formerly I should have considered this difference an absolute bar to the identity of the species. Recently, however, I have had the opportunity of studying the development of two species of Arnoglossus, in the larval condition of which the reticulo-papillate condition may be even more strongly marked than in Species F, and I find that the condition is variable, not only in individuals, but in the same individual. Certain circumstances, which I cannot clearly associate with the health of the individual, operate in such a way as to render the degree in which the epidermal peculiarities are apparent a matter of no value for specific identification. Thus, while I do not feel in a position to positively affirm the identity of all examples of Species $\mathrm{F}$ with $P$. unimaculatus, I am strongly of opinion that some, at least, of them may have belonged to that species.

I have remarked that the ova of $P$. unimaculatus, taken from one female, had yellow oil-globules. Probably all observers of Teleostean embryology will agree that the presence or absence of colour in the globules is of no specific moment.

* McIntosh and Masterman, British Marine Food Fishes, p. 348, 
I have long ago pointed out the resemblance between Species F (my Species xii., Trans. R. Dub. Soc., loc. cit.) and the series of metamorphosing larvæ which I described and figured (op. cit., p. 104, pl. xi.) under the title of Species xiii., and, in discussing the probable affinities of the latter, I was led to the belief that they were the young of $P$. unimaculatus. Whether or no they are identical with all specimens which have been included in Species F, I do not feel qualified to decide, but a comparison with the actual larva of $P$. unimaculatus inclines me strongly to the opinion that this species is the parent of the metamorphosing series comprised in Species xiii. Without the assistance of figures it is idle to discuss the matter farther, but I hope soon to have an opportunity of enforcing my own opinion by the illustration of my material.

\section{Arnoglossus laterna.-Günther.}

It is only quite recently that the developing ova and larvæ of the scaldfish have come under the notice of naturalists. Raffaele certainly observed the ovarian eggs of several species of Arnoglossus, of which A. conspersus was presumably one. The latter, if not identical with, is at least very closely allied to the common Atlantic species; but in any case, Raffaele failed to secure the embryo or larva, either by artificial impregnation or by the use of tow-nets.

During the summer of 1895 I was led to the conclusion that certain tow-net eggs from the Gulf of Marseilles must belong to $A$. conspersus, but the publication of my results has been anticipated by Dr. Ehrenbaum, who has recently (op. cit., p. 298), described the earliest stages of A. laterna from Heligoland. Petersen (Rep. Dan. Biol. St., 1894, p. 44) had already obtained the ripe ovarian ova, but was fain to content himself with a naked eye observation thereof, while Ehrenbaum was obliged to rely on tow-net material. There is, nevertheless, no doubt as to the correctness of his diagnosis.

In British waters the spawn of this fish has hitherto entirely escaped attention. During the Irish survey, though I obtained many specimens, I never saw a ripe female, and on this coast, where the species is even more abundant, there is no record of any observation of its reproduction. Moreover, of the many undetermined species of eggs which have from time to time been described by British writers, none can possibly be assigned to the scaldfish.

So far as concerns the observation of fish in the process of reproduction, I am now able to supply the deficiency, but have never been able to hatch artificially fertilized eggs.

On the 1st and 2nd June, in Teignmouth and Tor Bays, we trawled a number of ripe examples of both sexes of the undifferentiated form originally defined by Günther as A. laterna. 
Ova were taken from five females, $5 \frac{1}{2}$ to $6 \frac{1}{2}$ inches long, and impregnated with milt from three males, 5 to $5 \frac{1}{4}$ inches.

The ova underwent the early phases of segmentation, but died before the formation of the head. Half an hour after fertilization six specimens measured from 675 to $690 \mathrm{~mm}$. in diameter, the single oilglobule measuring 14 to $\cdot 15 \mathrm{~mm}$. It was dark, with a smoky margin, but quite devoid of colour. The yolk and zona presented no feature of importance.

On the 9th July, in the outer part of Falmouth Bay (Echinus and Pecten ground) we trawled a number of scaldfish chiefly of the differentiated form once known as A.lophotes, Gthr., with a few of the smaller undifferentiated type. The same experience was repeated on the 10th July.

On each occasion I found that the larger differentiated forms comprised some females from which the eggs could readily be extruded. They measured from $6 \frac{1}{8}$ in. to $6 \frac{5}{8}$ in., and exhibited a distinct prolongation of the anterior dorsal rays. The smaller females of the $A$. laterna type were two in number, and measured $5 \frac{1}{8}$ in. to $5 \frac{3}{8}$ in. These were also full of spawn, but not quite ready for extrusion.

Ova were obtained from two of the large females and impregnated with milt from a number of large males $6 \frac{3}{4}$ in. to $7 \mathrm{in.} \mathrm{long;} \mathrm{and}$ although the testes appeared to be ripe, I found, as also with the small males of the Devon coast, that milt could only be obtained by removing the organs and squeezing them in water. About seven hours later I measured six eggs, which appeared to have been successfully fertilized. The diameter ranged from 75 to $76 \mathrm{~mm}$; that of the oil-globule from 12 to $\cdot 13 \mathrm{~mm}$. Apart from dimensions, the ova were in all respects similar to those of the smaller forms, save that the zona appeared rather thicker in the latter. A number of the eggs survived for nearly a day, but were subsequently killed, as I suppose, by the intense heat of the 10th July. It was noted that they floated buoyantly in the water of the outer part of the bay, but without crowding at the surface of the vessel in which they were placed.

It is necessary to remark, in the first place, that my observations deal only with a few individuals, and that I do not know exactly, having mixed the ova obtained from the several specimens, to how many parents those measured should be ascribed. Such as they are, the results suggest that the smaller females produce smaller eggs (which is known to be the case, teste Maitland, in individuals of the Salmonidæ). A much more remarkable suggestion is that the eggs of the $A$. lophotes type have smaller globules than those of the undifferentiated $A$. laterna; but this may prove to be merely a matter of variety, or may be explained by developmental physiological NEW SERIES,-VOL v. No, 1 ,

rella expansa, which I had no difficulty in finding by following the directions given by Joyeux-Laffuie. The tube should be slit open, and a thin lamella of its substance, stripped off from the inner side, should be examined with the microscope. Even if the delicate zocecia are torn by the operation, or if the lamella be too thin to include any zoccia, the presence of the Polyzoon may be recognized by the holes through which the tentacles can be protruded into the interior of the tube. Each of these holes appears to the naked eye as a minute, opaque, white spot. The spotted appearance of the inside of the tube is a convenient indication of the presence of the Hypophorella, which can at once be recognized by the very long, thread-like connexions between the zoœcia, and by the two curious vesicular cavities which occur, one on either side of the distal end of the zoœcium. Excellent figures of 
changes of which I have no knowledge. For the present I have been prevented by bad weather from obtaining such a series of examples as would enable us to state the relation of dimension of egg to that of parent with anything like certainty.

It has already been suggested by Calderwood and myself (Trans. R. Dub. Soc., v. p. 504) that the absence of the $A$. lophotes type from regions, e.g. Scandinavia, where $A$. laterna is well known, is quite intelligible in the light of Maitland's researches on S. levenensis; and I think that the establishment of well-marked differences in the dimensions of the ova from large and small scaldfish parents would go far to support this view.

The tow-nets have not yielded any scaldfish eggs at the times when spawning fish have been trawled, and, indeed, I have only found the egg on two occasions in British waters. Ehrenbaum failed to obtain the eggs at the surface on any occasion, and, concluding that they might be confined to the deeper layers of water, secured them finally by the use of the vertical net between 18 and $40 \mathrm{~m}$. (say 9 to 22 fathoms). I have not been able to keep artificially fertilized eggs long enough to speak with certainty as to their specific gravity throughout the developmental period, but I have no hesitation in saying that the buoyancy of an egg in ordinary off-shore sea-water is subject to fluctuations which are explicable neither by species, degree of development, nor obvious physical and meteorological causes. I have not actually seen scaldfish eggs at the surface, but on the 6th June I found newly-hatched larvæ of $A$. laterna amongst ova and larvæ taken at the surface (four miles south of the Plymouth Mewstone) two days previously. The only other egg obtained was taken in the bottom tow-net on the 30th June, about two miles off Fowey river. The larvæ hatched from these eggs agree exactly with Ehrenbaum's figure of A. laterna, as also with the Mediterranean forms, which I myself associate with $A$. conspersus. The ova and larvæ of $A$. Grohmanni must undoubtedly exist on our coasts, and it may therefore be of use to point out that the larva (as I hope shortly to show in a communication to the Annales Mus. Nat. Hist. Marseille) is readily distinguished from that of $A$. laterna by the presence of two post-anal pigment bands. It is, in fact, the larva figured by Raffaele as hatched from ova resembling those of various species of Arnoglossus and of Rhomboidichthys and Citharus.

\section{Note added in Press.}

Arnoglossus Grohmanni.-Two eggs, which proved to belong to this species, were taken at the surface on the 27th July between the Eddystone and Hand Deeps. 